\title{
Diagnostic Accuracy of Ultrasound in Retained Products of Conception in Postpartum Period by Taking Histopathology as Gold Standard
}

\author{
Saba Sohail ${ }^{1}$, Mohsin Hussain², Ghazala Shahzad³ ${ }^{3}$ Abid Ali Sahito ${ }^{4}$, Sasui Memon5, Asma Jatoi ${ }^{6}$ \\ ${ }^{1}$ Department of Radiology, Dow University of Health Sciences Karachi-Pakistan, ${ }^{2}$ Department of Radiology, Pir Abdul Qadir Shah Jeelani Institute of Medical Sciences Gambat Khairpur- \\ Pakistan, ${ }^{3}$ Department of Radiology, Liaquat University of Medical \& Health Sciences, Jamshoro-Pakistan, ${ }^{4,6}$ Department of Radiology, Bilawal Medical College, LUMHS, Jamshoro- \\ Pakistan, 5Department of Radiology Advance Diagnostic Center, BMC, LUMHS Jamshoro-Pakistan
}

\begin{abstract}
Background: Retained product of conception (RPOC) has been the commonest factor involved in secondary post-partum hemorrhage. Ultrasound is a valuable diagnostic method for the diagnosis of PPH patients and is much more reliable than clinical presentation for the RPOC diagnosis alone. Objective: To determine the diagnostic accuracy of ultrasound in detection of retained products of conception in postpartum period in clinically suspected patients taking histopathology as gold standard. Study Design: Cross-sectional study. Settings: Radiology Department, Civil Hospital, Karachi Pakistan. Duration: From 5 th February 2017 to $4^{\text {th }}$ August 2017. Methodology: Total 135 patients with clinical suspicion of retained product of conception were included. Sonography was performed. D \& C was performed and specimen sent for histopathology. The diagnostic accuracy of ultrasound was established regarding specificity, sensitivity, NPV, PPV, against histopathology. Post stratification chi square test was applied and p-value $\leq 0.05$ was considered as significant. Results: The mean age of patients was $31.84 \pm 7.91$ years. Mean duration of symptoms was $3.48 \pm 1.44$ weeks. By ultrasound, $64.4 \%$ were diagnosed retained products of conception and by histopathology $54.8 \%$ were diagnosed. There were 65 true positive patients and 39 true negative patients. Specificity, Sensitivity, NPV, PPV, and accuracy were $63.9 \%, 87.8 \%, 81.2 \%, 74.7 \%$, and $77 \%$ respectively. Conclusion: Ultrasonography was observed as a reliable diagnostic tool showed accuracy rate of $77.0 \%$ with $87.8 \%$ sensitivity and $63.9 \%$ specificity, in the diagnosis of retained products of conception (RPOC).
\end{abstract}

Keywords: Diagnostic accuracy, Ultrasound, Retained products of conception in postpartum period, Histopathology.

Corresponding Author Submitted for Publication: 13-11-2019

Dr. Mohsin Hussain, Senior Registrar of Radiology, Pir Abdul Qadir Shah Jeelani Institute of Medical Sciences Gambat Khairpur-Pakistan Email: docmohsinkhoso@gmail.com

Citation: Sohail S, Hussain M, Shahzad G, Sahito AA, Memon S, Jatoi A. Diagnostic Accuracy of Ultrasound in Retained Products of Conception in Postpartum Period by Taking Histopathology as Gold Standard. APMC 2020;14(3):277-80.

\section{DOI: 10.29054/APMC/2020.723}

\section{INTRODUCTION}

Pregnancy loss is a significant psychological urgent situation in obstetrics. ${ }^{1}$ A major clinical problem is accurate diagnosis for retained pregnancy products (RPOC). ${ }^{1}$ Since rpoC can lead to endometritis, prolonged bleeding, and subsequent intrauterine adhesions with reduced possibility of future fertility, hence making treatment mandatory. ${ }^{2}$

In a study dealing with retained placental and products of conception, it was found that $47 \%$ of the cases of RPOCs followed vaginal delivery, however other less common causes included those after Cesarean section, first trimester pregnancy termination and second trimester pregnancy termination. ${ }^{3}$ The most frequent factor of secondary post-partum hemorrhage was RPOC. ${ }^{4}$ Clinical presentation of dilated cervical canal, vaginal bleeding, and typical ultrasound outcomes are the key tools in the RPOC diagnosis. Females are generally recommended for hysteroscopy or curettage; both of these are performed and require surgical procedure under general anaesthesia. ${ }^{5}$

Post-abortion care for missed and incomplete abortion can be done surgically, medically with misoprostol or expectantly by awaiting spontaneous expulsion. Surgical evacuation is an effective method with more than $95 \%$ success rate. ${ }^{6}$ Ultrasound is a valuable diagnostic method for the diagnosis of $\mathrm{PPH}$ patients and is much more reliable than clinical presentation for the RPOC diagnosis alone. The combination of gray-scale and color Doppler ultrasonography is the first-line diagnostic tool for suspected RPOC and enables blood flow and uterine structures to be assessed in real time. The ultrasound finding of hyper echoic material is most common finding indicating RPOCs. ${ }^{7}$ Ultrasonographic findings for discrete mass within uterine cavity or echo complex of endometrium thickness, is a valuable finding of gray-scale Ultrasound, which indicates RPOC. The endometrial mass or thickened EEC vascularity detection at power or color Doppler ultrasonography strengthens the PPV for RPOC diagnosis. The existence of chorionic villi, suggesting chronic trophoblastic or placental tissue, is the basis for the RPOC-associated pathologic diagnosis. ${ }^{8}$

Different studies have showed variation in the specificity and sensitivity of RPOC's ultrasonography detection. The specificity and sensitivity of ultrasonography in detecting RPOC was $73.9 \%$ and $93.8 \%$ respectively in one study ${ }^{9}$ while another study showed sensitivity of $44 \%$ and specificity of $92 \%$ using sonographic description of RPOC. ${ }^{10}$

Many studies have been done to establish the worth of ultrasonography in intrauterine contents diagnosis in cases of retained products of conception, shows considerable variability ${ }^{9,10}$ in sensitivity and specificity. As previous studies ${ }^{9,10}$ 
had been performed were conducted on detection of RPOC by ultrasound after vaginal delivery and our study was different because we aimed at determining the diagnostic accuracy among patients with caesarian section.

\section{METHODOLOGY}

Study Design: Cross-sectional study.

Settings: This study was conducted in Radiology department, Civil Hospital, Karachi Pakistan.

Duration: Six months from $5^{\text {th }}$ February 2017 to $4^{\text {th }}$ August 2017.

Sample Technique: Non-probability consecutive sampling.

Sample Size: By taking 93.8\% sensitivity ${ }^{9}$ and $73.9 \%$ specificity ${ }^{9}$ ultrasound in detection of RPOCs, prevalence of $47 \%{ }^{3}$, and confidence interval of $95 \%$ and desired precision of $5 \%$ for sensitivity and $10 \%$ for specificity, the calculated sample size was 135 .

Inclusion Criteria: Married female patients of 16 - 45 years and patients presenting with clinical suspicion of retained product in postpartum period after cesarean section were included.

Exclusion Criteria: Patients presenting after vaginal delivery, patients with known uterine pathologies like fibroid or cervical mass diagnosed on ultrasound and patients with twin pregnancy were excluded.

Data Collection Procedure: After taken approval from CPSP synopsis approval, patients meeting the inclusion criteria, referred to the department of Radiology, Civil Hospital Karachi for sonography at our department were enrolled in the study following informed consent from the patient. Patient's relevant history, clinical information were recorded on standard Performa. Sonography either with a convex transducer or endocavity transducer was undertaken on Toshiba Applio/Xario system. Images were obtained and documented by senior faculty/residents. D\&C was performed at our institution and specimen sent for histopathology. Results of the histopathology reports were followed and were recorded on Proforma.

Data Analysis Procedure: Data was entered and analyzed using (SPSS) statistical package version 21 software. Mean and standard deviation were calculated for parity, age, and symptoms duration. Post stratification, a $2 \times 2$ table was used in calculating the specificity, sensitivity and negative and positive predictive values, and diagnostic accuracy of sonography were determined taking histopathology as benchmark. Effect modifiers were controlled through stratification of age, duration of symptoms after delivery and parity to investigate their effect on outcome variables.

\section{RESULTS}

Total 135 study subjects with age 16-45 years were studied. Mean age of study subjects was $31.84 \pm 7.91$ years, most of the patients having age more than 30 years.

Out of all $78(58.0 \%)$ patients were seen with parity more than 3 . Majority of the cases $98(73.0 \%$ ) had history of RPOC less than 4 weeks. Table 1
Table 1: Demographic information of the patients $n=135$

\begin{tabular}{|c|c|c|}
\hline \multicolumn{2}{|c|}{ Variables } & Frequency (\%) \\
\hline \multirow{3}{*}{ Age groups } & $\leq 30$ years & $72(53.0 \%)$ \\
\cline { 2 - 3 } & 30 years & $63(47.0 \%)$ \\
\cline { 2 - 3 } & Mean+SD & $31.84+7.91$ \\
\hline \multirow{2}{*}{ Parity } & $1-3$ & $57(42.0 \%)$ \\
\cline { 2 - 3 } & $>3$ & $78(58.0 \%)$ \\
\hline $\begin{array}{c}\text { Duration of } \\
\text { symptoms }\end{array}$ & $\leq 4$ weeks & $98(73.0 \%)$ \\
\cline { 2 - 3 } & $>4$ weeks & $37(27.0 \%)$ \\
\hline
\end{tabular}

Out of all $64.4 \%$ were diagnosed retained products of conception by ultrasound and as far as histopathology is concerned, $54.8 \%$ were diagnosed with retained products of conception as presented in Table 2.

Table 2: Retained products of conception (RPOC) diagnosed on ultrasound and histopathology $(n=135)$

\begin{tabular}{|c|c|c|}
\hline \multicolumn{2}{|c|}{ Variables } & Frequency (\%) \\
\hline \multirow{2}{*}{$\begin{array}{c}\text { RPOC On } \\
\text { ultrasound }\end{array}$} & Yes & $87(64.4 \%)$ \\
\cline { 2 - 3 } $\begin{array}{c}\text { RPOC On } \\
\text { histopathology }\end{array}$ & No & $48(35.6 \%)$ \\
\cline { 2 - 3 } & Yes & $74(54.8 \%)$ \\
\hline
\end{tabular}

Sensitivity, Specificity, Predictive values and diagnostic accuracy of ultrasound for detection of retained products of conception by taking histopathology as gold standard were calculated. The results showed that there were 65 patients were true positive, correctly diagnosed and 39 patients were true negative, correctly diagnosed. Sensitivity, Specificity, PPV, NPV and accuracy were $87.8 \%, 63.9 \%, 74.7 \%, 81.2 \%$, and $77 \%$ respectively. Table 3.

Table 3: Diagnostic accuracy of ultra sound by taking histopathology as gold standard $(n=135)$

\begin{tabular}{|l|l|l|l|l|}
\hline \multirow{2}{*}{$\begin{array}{l}\text { Diagnosis of RPOC } \\
\text { by ultrasound }\end{array}$} & \multicolumn{3}{|l|}{$\begin{array}{l}\text { Diagnosis of RPOC } \\
\text { by histopathology }\end{array}$} & \multirow{2}{*}{ P-value } \\
\cline { 2 - 4 } & Yes & No & TOTAL & \multirow{2}{*}{0.001} \\
\hline Yes & 65 & 22 & 87 & \multirow{2}{*}{ A } \\
\cline { 1 - 4 } No & 9 & 39 & 48 & \\
\hline Total & 74 & 61 & 135 & \\
\hline Sensitivity & Specificity & PPV & NPV & Accuracy \\
\hline $87.8 \%$ & $63.9 \%$ & $74.7 \%$ & $81.2 \%$ & $77.0 \%$ \\
\hline
\end{tabular}

\section{DISCUSSION}

In the emergency unit, postpartum symptoms are usual. The retained product of conception (RPOC) is among the most significant differential factors in such patients. When a postpartum individual has indications of endometritis or hemorrhage, particularly bleeding, vaginal discharge, or pelvic 
pain, and fever, RPOC must be suspected.11,12 In our study, study subjects were found to have $31.84 \pm 7.91$ years of mean age, most of the patients having age more than 30 years. Similarly, lqbal $\mathrm{H}$ et al ${ }^{1}$ stated mean age of study patients was $28.62+5.64$ years. On other hand Karimpour $\mathrm{M}$ et $\mathrm{a}^{13}$ reported $29.3 \pm \overline{5} .7$ years of mean age, $17 \pm 12.38$ weeks of mean gestational age and median parity was 2 , these findings were close to the results of this study regarding mean age, mean gestational age and parity. Esmaeillou $\mathrm{H}$ et al ${ }^{14}$ also reported that mean age of RPOC patients was $28.1 \pm 4.8$ years.

In this study sensitivity ultrasonography showed specificity, sensitivity, NPV, PPV and accuracy were $63.9 \%, 87.8 \%, 81.2 \%$, $74.7 \%$, and $77 \%$ respectively by taking histopathology as gold standard. On other hand Esmaeillou $\mathrm{H}$ et al ${ }^{14}$ reported that the specificity, sensitivity, and NPV and PPV with $95 \%$ confidence intervals of vascularity for RPOC detection were $68 \%, 88 \%$, $88 \%$ and $67 \%$ respectively. However, Karimpour $M$ et al ${ }^{13}$ reported that ultrasound has a diagnostic accuracy, sensitivity, specificity, PPV and NPV of $74.09 \%, 75.22 \%, 72.50 \%, 79.44 \%$, and $67.44 \%$, respectively. On other hand QAZI AS et al ${ }^{15}$ conducted study on diagnostic accuracy of TVU and observed that the transvaginal ultrasound with histopathology showed specificity, sensitivity, PPV, NPV and diagnostic accuracy of Transvaginal Ultrasound were 96.05\%, 97.6\%, 96.4\%, 97.3\% and $96.8 \%$ respectively.

Because of its accessibility, safety, and cost advantages, ultrasonography is a preferred diagnostic tool for assessing febrile postpartum patients. In emergency departments, though the accessibility of radiology could be limited and the frequent utilization of bedside ultrasonographic imaging by emergency physicians would translate well into this use. ${ }^{11}$ Hyperechoic, intrauterine material involving internal vascularity found with Color-Doppler and low-resistance flow, high-velocity via spectral Doppler are usual sonographic findings. Blood products can have an echogenic presentation similar to that however without internal flow. For RPOC, the existence of vascularity has a PPV of $96 \%$, as per Kamaya et al. A uterine evacuation could be appropriate in suspected RPOC. Using suction or sharp curettage, it can be done. When the bedside ultrasonographic examination is incorrect, antibiotics as well as close monitoring could be appropriate. Surgical operation may be prevented when there is a good response to antibiotics within initial 24 hours. ${ }^{15}$ Perhaps in the surgical effort to eliminate them, we diagnose RPOC excessively and subject patients to needless trauma. The effects of recurrent curettage are instantaneous complications like bleeding, infection, and perforation and late complications like infertility and intrauterine adhesions. For overt infection cases, excessive bleeding or severe abdominal pain and those whose symptoms do not respond to conservative measures, the surgical choice must be reserved.

\section{CONCLUSION}

It was concluded that ultrasonography is the reliable and noninvasive diagnostic tool showed accuracy rate of $77.0 \%$ with $87.8 \%$ sensitivity and $63.9 \%$ specificity, in the diagnosis of retained products of conception (RPOC) Ultrasonographic (US) assessment can be especially beneficial in cases suspected of RPOC and a discrete uterine cavity mass or thickened endometrial echo complex (EEC), as per the study findings, is a supportive gray-scale Ultrasonography finding that indicates RPOC. The existence of a endometrial mass or thickened EEC with detectable vascularity at power and colour Doppler ultrasonography imagining allows for assured diagnosis of RPOC, despite an adequate clinical history.

\section{LIMITATIONS}

The limitation of this analysis is that, it was performed in urban settings on a small scale and thus the results might not be generalizable to larger populations.

\section{SUGGESTIONS / RECOMMENDATIONS}

Our results suggested that ultrasonography could be used for detection of retained products of conception (RPOC). Further large sample size studies are suggested on this subject.

\section{CONFLICT OF INTEREST / DISCLOSURE} None.

\section{ACKNOWLEDGEMENTS}

No.

\section{REFERENCES}

1. Iqbal H, Khan MS, Muneeb A, Mirza WA. Diagnostic accuracy of ultrasound in detecting retained products of conception: A study from a tertiary care hospital in Karachi, Pakistan. Cureus. 2018;10(11);2-8

2. Tsui KH, Lin LT, Cheng JT, Teno SW, Wang PH. Comprehensive treatment for interfile women with severe Asherman's syndrome. Taiwan J Obstet Gynecol. 2014;53:372-5.

3. Fejgin MD, Shivat TY, Gershtansky Y, Shental TB. Retained placental tissue as an Emerging cause for malpractice claims. IMAK. 2014;16(8):502-5.

4. Edhi MM, Aslam HM, Naqvi Z, Hashmi H. Post partum haemorrhage: causes and management BMC Research notes. 2013:6:236

5. Wolman I, Altman E, Faith G, Har-Togy J, Gull I, Jaffa AJ. Combined clinical and ultrasonographic work-up for the diagnosis of retained products of conception. Fertil Steril. 2009;92:1162-4.

6. Bano K, Talat, Iqbal S. Alternative to surgical evacuation of uterus: misoprostol for post-abortion care. J Surg Pakistan (International). 2009;14:53-7.

7. Sellmyer MA, Desser TS, Maturen KE, Jeffery RB, Kamay A. Physiologic, histologic and imaging features of retained products of conception. RadioGraphics. 2013;33:781-96.

8. Wong SF Lam MH, Ho LC. Transvaginalsonography in the detection of retained products of conception after first-trimester spontaneous abortion. J Clin Ultrasound. 2002;30(17):428-32.

9. Shen $O$, Rabinowitz $R$, Eisenberg $V H$, Samuiloff $A$. Transabdominal sonography before uterine exploration as a predictor of retained placental fragments. J Ultrasound Med. 2003;22:561-4. 
10. Carlan SJ, Scott WT, Pollack R, Harris K. Appearance of the uterus by ultrasound immediately after placental delivery with pathologic correlation. J Clin Ultrasound. 1997;25:301-8

11. Adkins K, Minardi J, Setzer E, Williams D. Retained Products of Conception: An Atypical Presentation Diagnosed Immediately with Bedside Emergency Ultrasound. Case reports in emergency medicine. 2016;2016: Article ID 9124967.

12. Durfee SM, Frates MC, Luong A, Benson CB. The sonographic and color Doppler features of retained products of conception. Journal of ultrasound in medicine. 2005;24(9):1181-6.

13. Karimpour M. Accuracy of trasvaginal sonography in detecting retained products of coception in correlation with pathologic findings and clinical examination. PJR. 2016;20(3);130-33.

14. Esmaeillou H, Jamal A, Eslamian L, Marsousi V, Sarvi F, Kokab A. Accurate detection of retained products of conception after first-and second-trimester abortion by color Doppler sonography. Journal of Medical Ultrasound. 2015;23(1):34-8.

15. Qazi AS, Sami S, Akhtar S. Diagnostic accuracy of transvaginal ultrasound in clinically suspected cases of retained products of conception. Pak Postgrad Med J. 2013;24(1):17-21.

\section{AUTHORSHIP CONTRIBUTION}

\begin{tabular}{|l|l|}
\hline $\begin{array}{l}\text { Dr. Saba Sohail } \\
\text { Professor of Radiology, Dow University } \\
\text { of Health Sciences Karachi Pakistan }\end{array}$ & $\begin{array}{l}\text { Supervision, Critical Review, } \\
\text { Proof Reading }\end{array}$ \\
\hline $\begin{array}{l}\text { Dr. Mohsin Hussain } \\
\text { Senior Registrar, Radiology } \\
\text { Pir Abdul Qadir Shah Jeelani Institute } \\
\text { of Medical Sciences Gambat Khairpur } \\
\text { Pakistan }\end{array}$ & $\begin{array}{l}\text { Study Designing, Data } \\
\text { Collection }\end{array}$ \\
\hline $\begin{array}{l}\text { Dr. Ghazala Shahzad } \\
\text { Assistant Professor, Radiology } \\
\text { Liaquat University of Medical \& Health } \\
\text { Sciences, Jamshoro Pakistan }\end{array}$ & $\begin{array}{l}\text { Authentication of References } \\
\text { Statistical Analysis }\end{array}$ \\
\hline $\begin{array}{l}\text { Dr. Abid Ali Sahito } \\
\text { Assistant Professor, Radiology } \\
\text { Bilawal Medical College, LUMHS, } \\
\text { Jamshoro Pakistan }\end{array}$ & Results and Discussion \\
\hline $\begin{array}{l}\text { Dr. Sasui Memon } \\
\text { Consultant Radiologist, Advance } \\
\text { Diagnostic Center, BMC, LUMHS } \\
\text { Jamshoro Pakistan }\end{array}$ & Tabulation of Results, \\
\hline $\begin{array}{l}\text { Dr. Asma Jatoi } \\
\text { Senior Registrar, Radiology } \\
\text { Bilawal Medical College, LUMHS, } \\
\text { Jamshoro Pakistan }\end{array}$ & Designing Charts and Figures \\
\hline
\end{tabular}

